\title{
Practicing Pediatric Pathology Without a Microscope
}

\author{
Raj P. Kapur, M.D., Ph.D.
}

University of Washington, Seattle, Washington

This article highlights changes in the field of pediatric pathology that have resulted from technical advances in prenatal diagnostics, immunohistochemistry, cytogenetics, and molecular genetics. The relatively new and growing need for specialized training in fetal pathology is used as an example. Comprehensive evaluation of human fetuses has become a requisite skill for many diagnostic pathologists, in part because contemporary prenatal diagnostic techniques have shifted the demographics of many congenital conditions from spontaneous term delivery to mid-gestation termination of pregnancy. The information provided by the pathologist has a tremendous impact for families and clinicians as they consider recurrence risks in future pregnancies. As most specimens from therapeutic terminations have gross dysmorphology, which may or may not constitute a recognizable pattern of human malformation, their analysis requires additional skills and methods that were traditionally the domain other specialists (e.g., medical geneticists). The pathologist must learn to identify syndromes, to be aware of their underlying etiology and pathogenesis, and to utilize advanced cytogenetic methods (e.g., fluorescence in situ hybridization), flow cytometry, or specific mutational analysis when appropriate. At a minimum, important anatomic details must be well documented and appropriate tissue samples should be obtained and stored to facilitate more specific diagnostic testing in the future.

KEY WORDS: Syndromology, Malformation, Fanconi anemia, Velocardiofacial syndrome, Fetal dyskinesia.

Mod Pathol 2001;14(3):229-235

Copyright $\odot 2001$ by The United States and Canadian Academy of Pathology, Inc.

VOL. 14, NO. 3, P. 229, 2001 Printed in the U.S.A.

Date of acceptance: December 12, 2000.

Address reprint requests to: Raj P. Kapur, M.D., Ph.D., Department of Pathology, Box 357470, University of Washington Medical Center, 1959 NE Pacific Street, Seattle, Washington 98195; e-mail: kapur@u.washington.edu; fax: 206-543-3644.
The practice of anatomic pathology is constantly in flux and the beginning of this new millennium is no exception. In pediatric pathology, as in other medical disciplines, molecular genetics has dramatically altered the way we handle, diagnose, and prognosticate from specific specimens. The application of molecular diagnostic techniques to pediatric neoplasia including solid and hematologic malignancies is generally similar to adult pathology and has been reviewed in accompanying papers from this course. However, the anatomic pathology of congenital disorders remains largely a field for pathologists who serve the newly born or very young, including those of us who subspecialize in pediatric pathology. The theme of this paper will be the increasing demands that have been thrust upon the anatomic pathologist as a result of technical and sociologic changes in obstetrical management. Emphasis will be placed on traditional and modern nonhistologic approaches that are necessary for comprehensive evaluation of perinatal specimens. The suggestion will be offered that, in addition to knowledge of contemporary medical genetics, the next generation of pathologists needs more training in less "glamorous" skills such as gross description and dissection. In short, a "complete" pediatric pathologist in the 21 st century will embody attributes of the earliest anatomists and today's sophisticated molecular geneticist.

\section{Resurrecting the Autopsy}

As a pediatric pathologist whose principle clinical responsibility is perinatal pathology, I am acutely aware of the dynamic nature of pathology practice, because my specialty has changed as much as any other. Perhaps the most obvious change concerns the volume and type of specimens that we encounter (Table 1). Fetuses and placentas from elective terminations of pregnancy have increased similarly in number in other anatomic pathology practices, particularly at tertiary care centers. In large part, this added volume is a consequence of technical advances in prenatal diagnosis including screening maternal amniolytes, diagnostic ultrasound, and molecular genetics. 
TABLE 1. Therapeutic Abortuses Received for Pathological Evaluation at the University of Washington Medical Center

\begin{tabular}{cc}
\hline Year & Number of Cases* \\
\hline 1989 & 31 \\
1998 & 89
\end{tabular}

* In Washington state, elective termination of pregnancy cannot be performed after 24 weeks, unless a lethal fetal condition is identified or the mother's life is endangered by pregnancy continuation.

The point is made nicely in a recent study (Fig. 1) (1) and others $(2,3)$ that show a dramatic decline in the incidence of NTDs in liveborn infants. In each case, the authors attributed this change to improvement in prenatal diagnosis and second trimester termination, largely related to msAFP screening and ultrasound. The same is true for many other conditions (e.g., Trisomy 18, anencephaly, hypoplastic left heart, skeletal dysplasias). In the past, many of these same cases might have come to us to autopsy after neonatal or infantile demise. Still others were compatible with long-term survival and might have been seen by clinical specialists in dysmorphology, neurodevelopment, or other disciplines. With increasing frequency these patients are now entrusted to the pathologist, who in one "clinic" visit must collect all of the necessary data to arrive at as accurate a diagnosis as possible.

Concomitant with the changing volume and nature of perinatal specimens, pathologists have been required to develop specific skills and knowledge that are necessary for comprehensive anatomical study of these cases. When examining a malformed fetus, accurate gross description and thorough documentation of gross anatomical findings are paramount. Although histology is a component of fetal pathology, more often than not diagnosis and management hinges on gross findings and/or other ancillary techniques (e.g., cytogenetics, molecular di-

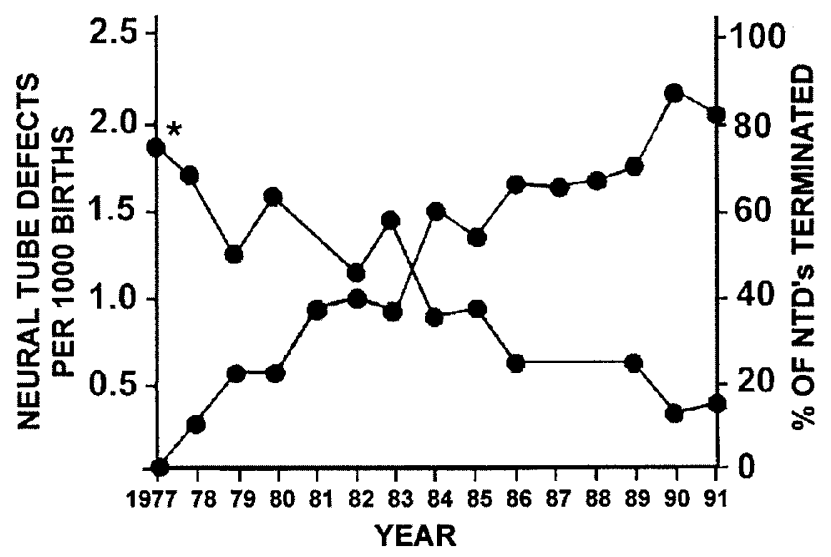

FIGURE 1. This figure is based on data from Chan et al., 1993 (1) and illustrates how the declining incidence of livebirths with neural tube defects over two decades correlates inversely with an increased frequency of therapeutic terminations of pregnancy for the same conditions. *Neural tube defects per 1000 births. agnostics). Unfortunately, many residency programs do not emphasize gross description and illustration. As such, many pathology reports lack necessary details that might allow recognition of a pattern of human malformation by a competent dysmorphologist.

The minimal goal of any pathologic study should be to collect and preserve anatomical information such that as specific a diagnosis can be rendered as possible. The report should explicitly describe external and internal gross anatomical features including many significant negative findings that might be take for granted in an older child or adult (e.g., number of digits). Most experienced pathologists develop a systematic approach to perinatal specimens that insures all pertinent parts of the body are examined (see Valdes-Dapena et al., 1997 (4) for an excellent example). When done right, examination of a fetus or neonate is a timeconsuming process that is generally not reimbursed in proportion to the amount of effort involved. As such, economic pressures often conflict with the interests of the patient and clinicians. Unfortunately, no simple solutions exist to this problem of inadequate resources and/or compensation and the reality is that pathologists remain responsible for documenting those anatomic details that may lead to a specific diagnosis with implications for living family members.

\section{A Scalpel in One Hand and a Camera in the Other}

I really believe there are things nobody would see if I didn't photograph them.

Diane Arbus, 1972

Our forefathers in the field of pathology were not only astute observers, but also talented artists. The detailed drawings that characterized pathologic treatises more than 100 years ago undoubtedly required many hours to create, but in their production forced the artist to attend to gross anatomical details that might be missed in the hectic pace of contemporary practice. However, we have the luxury of photography to capture similar information more accurately and quickly. My colleague, Dr. Joe Siebert (Children's Hospital and Regional Medical Center, Seattle), is fond of saying "a good photographic takes only a sixtieth of a second." Yet, when properly utilized this simple procedure can record information far more accurately and objectively than gross description alone. However, a big difference exists between any photograph and a "useful" photograph. Consideration must be given to composition of the photograph so as to include salient features at a suitable magnification and with appropriate lighting. A thoughtful photograph can facili- 
tate accurate diagnosis long after the gross examination is complete.

\section{Freeze Tissue!!!}

In addition to detailed gross descriptions and high quality photographs, procurement of a frozen tissue sample is an important component of perinatal pathology studies. At the University of Washington Medical Center, we routinely freeze a sample of liver and placenta from every case. Frozen tissue provides a source of DNA, RNA (less stable), proteins, and other molecules that may be used in a variety of ways (Table 2) (5).

The practice of routine freezing tissue arose in our laboratory because of the dramatic technical and diagnostic advances in molecular genetics. Each month, new associations are established between congenital phenotypes and mutations in specific genes. The pace of these new discoveries is daunting and difficult to monitor. In parallel with these discoveries, the potential to perform mutational analysis on a DNA sample from an affected fetus (or its placenta) exists. Molecular diagnosis of a particular mutation can have profound implications beyond confirmation of a clinical diagnosis. In many cases, it is technically possible to test parents or other relatives to identify carriers of a given mutation. The results of such tests can be used to provide accurate estimates for recurrence in subsequent pregnancies and to perform prenatal diagnosis in some instances.

The case illustrated in Figure 2 provides an example of the benefits of frozen tissue for the counseling and management of a hereditary disorder. The index patient in this family was a term infant who expired within an hour of birth of respiratory failure. Autopsy demonstrated bilateral enlargement of the kidneys with histolopathologic changes diagnostic of autosomal recessive polycystic kidney disease. At the time of autopsy, a liver sample was frozen. Although the gene for this disorder had not been cloned, it was mapped, so that when the couple became pregnant again, it was possible for a reference laboratory to perform linkage analysis using DNA extracted from a chorionic villous sample, the sibling's frozen liver, and DNA from the parents. These studies established a 95\% likelihood that the second fetus was affected and the pregnancy was electively terminated at 20 weeks gestation. Although prenatal ultrasonographic studies were inconclusive before termination, microanatomical studies of the fetal kidney confirmed recurrence of the renal malformation.

Given the myriad of specific genes that have been implicated in specific disorders, it is impossible to expect a pathologist to know the availability of a particular genetic test at the time of fetal examination. Furthermore, novel genetic tests may become available months to years after a case is evaluated, but at a time when family members are still interested. The pathologist can best serve the patient by freezing tissues at the time of autopsy and saving the frozen tissue for at least a year, such that appropriate testing can be solicited if desired. In many instances, request for the tissue will come from geneticists or genetic counselors, who integrate the anatomic pathology results with other clinical information from the family.

It should be noted that, at this time, many molecular diagnostic studies that can be done to exclude/confirm specific genetic defects have been developed in research laboratories, which either do not function as reference laboratories or do so on a highly restricted basis. The limited availability of specific tests can be frustrating for patients and pathologist. Two useful sources of information about genetic testing and laboratories that can perform specific molecular tests are GeneTests ${ }^{\mathrm{TM}}$ (www.genetests.org), a "genetic testing resource that includes a genetics laboratory directory, a resource list of genetics clinics, and an introduction to genetics counseling and testing concepts," and GeneClinics ${ }^{\mathrm{TM}}$ (www.geneclinics.org), a "medical knowledge base relating genetic testing to the diagnosis, management, and genetic counseling of individuals and families with specific inherited disorders." Both services are free to health care providers, but require a one-time registration.

\section{An Overly Simplified Approach to Fetal \\ Pathology in the New Millennium}

The guiding philosophy in my approach to perinatal specimens is to collect data as accurately and thoroughly as possible and preserve it so that an

TABLE 2. Potential Uses of Frozen Tissue Samples

\begin{tabular}{lll}
\hline \multicolumn{1}{c}{ Use } & Constituent & Example \\
\hline Electrophoresis & Hemoglobin & Thalassemia \\
Western blot & Viral protein & Human immunodeficiency virus \\
HPLC & Amino acids & Glutaric acidemia \\
GC-MS & Cholesterol & Smith-Lemli Opitz syndrome \\
Enzyme assay & Debrancher deficiency & Glycogen storage disease \\
Southern blot/PCR & LlCAM gene & X-linked aqueductal stenosis \\
Comparative Genomic Hybrid & DNA & Confined placental mosaicism \\
RT-PCR & RNA & Hirschsprung disease \\
\hline
\end{tabular}



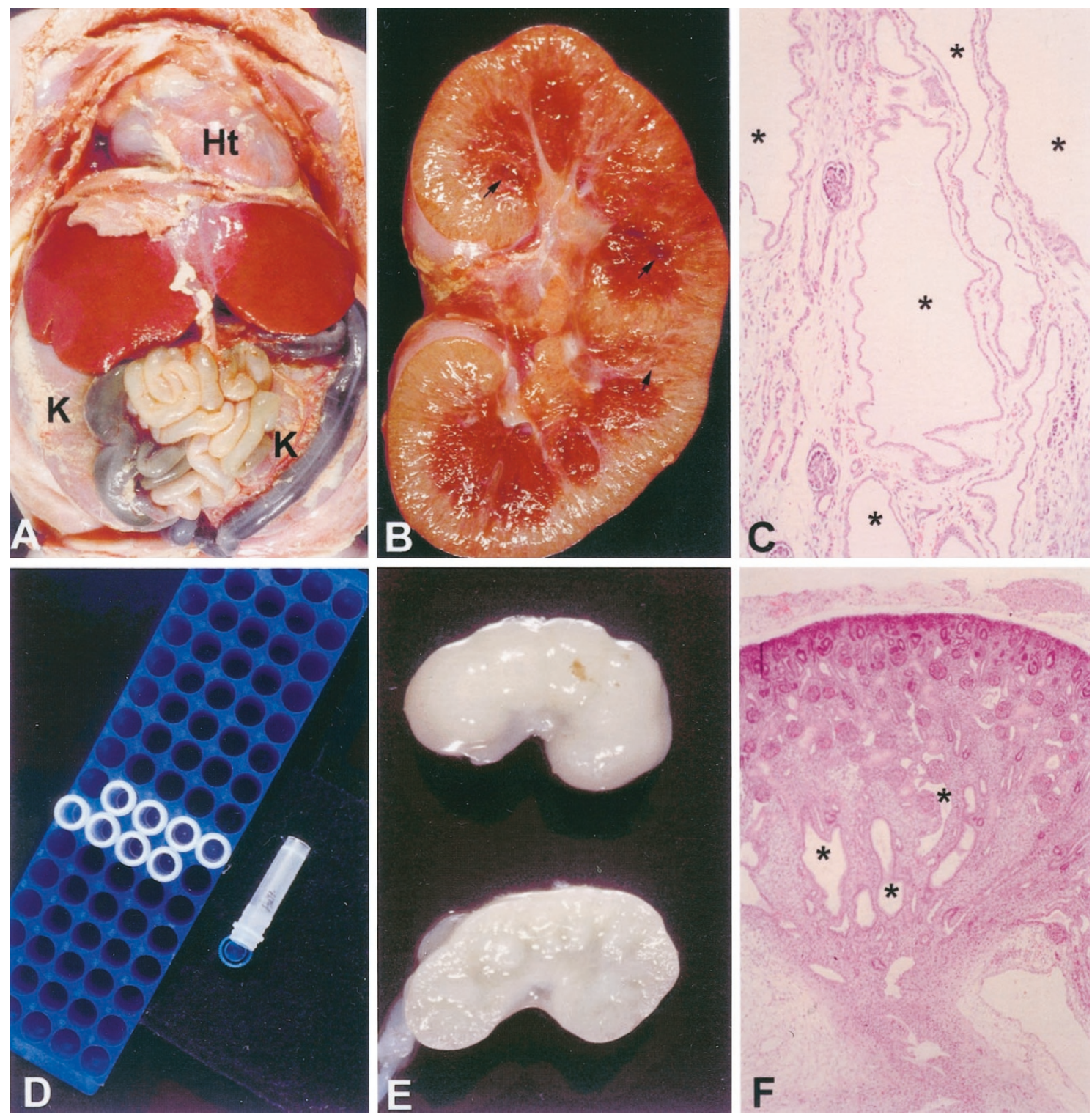

FIGURE 2. Practical value of frozen tissue samples. A, Internal organs of full-term infant with massively enlarged kidneys (K). The cut surface of the unfixed kidney (B) shows medullary cysts (arrows) and prominent radial markings that correspond histologically (C) to cystically dilated collecting ducts (asterisks) characteristic of autosomal recessive polycystic kidney disease. D, $1.5 \mathrm{~mL}$ tubes used to freeze liver from fetal cases, including the infant shown in (A). E, The external (top) and cut surfaces of a kidney from the sibling of the infant shown in (A). This fetus was electively aborted at 20 weeks gestation after molecular genetic studies, using DNA from the frozen liver sample, indicated a $95 \%$ chance that he would have the disease. Although neither the gross findings nor a prenatal ultrasound (not shown) were diagnostic, histologic studies of the fetuses kidney (F) demonstrated cystic transformation of collecting ducts (asterisks), and confirmed the molecular diagnosis. Ht, heart.

appropriate diagnosis can be reached. In line with this tenet, an effort is made to provide detailed gross descriptions, obtain useful photographs and radiographs, sample thoughtfully for histologic studies, and freeze tissue from every case. In doing so, materials sufficient to make most diagnoses are collected and retained in a form that can be analyzed and reanalyzed almost indefinitely. Eventually, the knowledge, expertise, or test necessary to achieve a specific diagnosis may be realized, possibly by persons other than the prosector (Fig. 3).

This approach is sufficient in most cases. However, a small but significant set of clinical presentations exists for which additional types of imme- diate action are either required or highly desired at the time of autopsy. These are listed in Table 3. Examples of conditions that absolutely require immediate action include fetal dyskinesia and fetuses with features of either Fanconi anemia or Roberts syndrome. As a subset of fetal dyskinesia cases are due to primary fetal myopathies, a comprehensive evaluation of such fetuses includes formal muscle pathology including histochemical studies and electron microscopy (if tissue can be obtained very soon after death). Muscle histochemistry protocols are described elsewhere (6) and require frozen sections of skeletal muscle. The histochemical properties of fetal skeletal muscle differ from postnatal 


\begin{tabular}{|c|c|}
\hline \multicolumn{2}{|l|}{ FOR EVERY FETAL CASE } \\
\hline $\begin{array}{l}\text { Detailed Gross Description and } \\
\text { Thoughtful Records } \\
\text { (written, radiographic, photographic) }\end{array}$ & $\begin{array}{l}\text { Freeze Sample of } \\
\text { Fetal Tissue and } \\
\text { Placenta }\end{array}$ \\
\hline \multicolumn{2}{|l|}{ AND IF THE PHENOTYPE } \\
\hline includes $\geq 2$ major malformations & THEN ... Fetal and / or placental cytogenetics \\
\hline suggests triploidy & THEN ... Fetal or placental flow cytometry \\
\hline suggests VCFS/DiGeorge & $\begin{array}{l}\text { THEN ... Fetal and / or placental cytogenetics } \\
\text { and fluorescence in situ hybridization }\end{array}$ \\
\hline suggests hypokinesia & $\begin{array}{l}\text { THEN ... Frozen skeletal muscle for } \\
\text { histochemistry }\end{array}$ \\
\hline includes a radial ray defect & $\begin{array}{l}\text { THEN ... Culture fetal and / or placental } \\
\text { tissues for chromosomal breakage } \\
\text { studies }\end{array}$ \\
\hline $\begin{array}{l}\text { is idiopathic moderate-to-severe } \\
\text { growth retardation and mother } \\
\text { does not smoke or have chronic } \\
\text { hypertension }^{2}\end{array}$ & $\begin{array}{l}\text { THEN ... Placental, cytogenetics to exclude } \\
\text { confined placental mosaicism }\end{array}$ \\
\hline
\end{tabular}

FIGURE 3. Overly Simplified Approach to Fetal Examination

specimens and mature during gestation, such that appropriate age-matched controls are often needed to interpret these cases.

Fanconi anemia and Roberts syndrome are both pleiotropic autosomal recessive conditions in which limb abnormalities are a common feature. Fifty percent of Fanconi anemia patients have radial ray defects (e.g., radial aplasia, hypoplastic thumb), which may be unilateral or bilateral. A wide variety of other anomalies are also observed in Fanconi anemia, which shares considerable phenotypic overlap with the VACTERL association $(7,8)$. Roberts syndrome is characterized by extremity abnormalities that range from radial ray defects to "seal-limb" malformations (9). Facial clefts are also common. Fanconi anemia and Roberts syndrome each are associated with characteristic chromosomal anomalies that can be detected cytogeneti- cally from cultured fetal cells (10-12). The differential diagnosis should be communicated to the cytogenetic laboratory along with the specimens because special treatments of the fetal cells may be required to perform the cytogenetic studies. Moreover, not all cytogenetic laboratories perform these studies, so samples may need to be sent to a reference laboratory. Fanconi anemia is a multigene disorder (13-15). Some of the genes have been cloned and mutational analysis has been conducted in some research laboratories (16). However, cytogenetic studies of chromosome breakage are still the most efficient way to confirm the diagnosis, given that some of the Fanconi genes have not been identified and mutational analysis for the cloned genes may not be accessible.

The other conditions listed in Table 3 represent chromosomal disorders in which immediate action, i.e., cell culture for cytogenetics, is highly desirable, but not essential to diagnosis. With the advent of comparative genome hybridization macrosomic chromosomal rearrangements or aneuploidy can be detected using DNA extracts from frozen tissue as a template. DNA from formalin-fixed tissues can also be used, but are less desirable. At this time, traditional cytogenetics is advisable because comparative genome hybridization is not widely utilized except primarily academic centers for research purposes. Furthermore, traditional cytogenetic studies will resolve many balance chromosomal rearrangements that will not be detected by comparative genome hybridization.

Velocardiofacial/DiGeorge syndrome is an autosomal dominant condition associated with incomplete penetrance and variable expressivity for a diverse set of malformations $(17,18)$. Conotruncal cardiac defects, cleft palate, and thymic hypoplasia/agenesis are prominent within the phenotypic

TABLE 3. Conditions that Require or Benefit from Immediate Action at the Time of Examination

\begin{tabular}{|c|c|c|}
\hline Condition & Common Features* & Action (Alternative) \\
\hline Fetal dyskinesia & $\begin{array}{l}\text { Multiple arthrogryposes pterygia, micrognathia, } \\
\text { hydrops, short umbilical cord }\end{array}$ & $\begin{array}{l}\text { Muscle biopsy workup: } \\
\text { Frozen sections for histochemistry } \\
\text { Electron microscopy }\end{array}$ \\
\hline Fanconia anemia & $\begin{array}{l}\text { Radial ray, renal, cardiac, other skeletal, } \\
\text { anorectal, duodenal atresia, hydrocephalus } \\
\text { tracheoesophageal fistula (similar to VACTERL } \\
\text { association) }\end{array}$ & Cultures for chromosome breakage \\
\hline Roberts syndrome & Phocomelia, facial clefts, growth restriction & $\begin{array}{l}\text { Cultures to study chromosome "puffing"/premature } \\
\text { centromere separation }\end{array}$ \\
\hline Velocardiofacial/DiGeorge syndrome & $\begin{array}{l}\text { Cleft palate, abnormal facies, conotruncal } \\
\text { cardiac, renal hypoplastic thymus }\end{array}$ & $\begin{array}{l}\text { Metaphase FISH for } 22 \mathrm{q} 11.2 \text { deletion (interphase FISH } \\
\text { from paraffin, Southern blot, PCR) }\end{array}$ \\
\hline Fetal chromosomal disorder & $\geq 2$ major malformations & $\begin{array}{l}\text { Cultures for cytogenetics (comparative genomic } \\
\text { hybridization) }\end{array}$ \\
\hline Placental aneuploidy & $\begin{array}{l}\text { Moderate-to-severe growth restriction }+/- \\
\text { stillbirth }\end{array}$ & $\begin{array}{l}\text { Placental cultures for cytogenetics (comparative } \\
\text { genomic hybridization) }\end{array}$ \\
\hline Triploidy & $\begin{array}{l}\text { Intrauterine growth restriction, adrenal } \\
\text { hypoplasia, small or partial molar placenta, } \\
\text { hydrocephalus, 3-4 syndactyly, and others }\end{array}$ & $\begin{array}{l}\text { Flow cytometry (can be done with fixed and } \\
\text { embedded tissue) }\end{array}$ \\
\hline
\end{tabular}

* Many of these conditions are characterized by variable phenotypes such that one or more "common feature" may not be present. 
spectrum. Dysmorphic facies is also a feature, but may not be apparent in a mid-gestation fetus. Velocardiofacial/DiGeorge should be considered when a fetus exhibits two or more of these findings and no other established etiology (e.g., chromosomal aneuploidy). An estimated $90 \%$ of Velocardiofacial/DiGeorge cases are associated with deletion 22q11.2 that can be resolved by fluorescence in situ hybridization. It is easiest technically to perform this analysis on metaphase chromosome spreads from cultured fetal cells, although alternative procedures are possible using frozen tissue (19, 20). Therefore, procurement of a suitable specimen is highly desirable at the time of examination. However, in the event that fresh tissue is not available, it is possible to perform interphase fluorescence in situ hybridization on nuclei extracted from paraffin blocks.

\section{Perinatal Medicine is a Team Sport}

In many medical centers, care for couples with a "high-risk" pregnancy is conducted by a team of skilled professionals that includes perinatologists, neonatologists, geneticists, social workers, radiologists, nursing staff, social workers, and ethicists. The pathologist is a key member of this group because he or she may be the only one to directly examine the fetus. Regular communication between the pathologist and other members of this team is imperative to insure that fetuses are handled optimally to facilitate anatomic evaluation and laboratory testing. The method of delivery, autopsy interval, special handling of tissue samples, need for cytogenetics, and other issues should be optimized based on antenatal discussions of individual cases. For example, many closed neural tube defects cannot be confirmed if a fetus is delivered by dilatation and evacuation because of trauma to the central nervous system. Clinicians and their patients are not always aware of such limitations and may choose an alternative method of delivery if pathologic confirmation is desired.

These discussions are a two-way street. The pathologist learns from the clinician vital information that affects examination and handling of a specimen. In this manner, the individual needs of certain cases for cell cultures, special dissections, biochemical tests, etc. can be anticipated.

\section{SUMMARY}

Although the volume and diversity of midgestation fetuses that require pathologic evaluation is increasing, the fundamental function of the anatomic pathologist for these cases is the same as for any specimen-confirm, exclude, and/or reveal pertinent diagnostic findings. Examinations should be approached with these goals in mind, although the skills that need to be applied may differ from those emphasized with other specimens. In particular, documentation of gross findings and preservation of genetic data are important aspects that need to be learned and practiced. Knowledge of the antenatal history and clinical questions is essential and is facilitated by direct contact with clinical colleagues. A routine that includes photography, radiography, and freezing tissue optimizes the opportunity to obtain a definitive diagnosis in most cases, particularly when molecular testing and/or expert consultation is required. Only a small and relatively rare group of clinical/anatomic presentations require other types of action at the time of gross examination. A pathologist who is aware of the latter situations and acts accordingly for appropriate cases will satisfy the needs of the parents and clinicians with minimal extra effort.

Acknowledgments: Much gratitude is extended to Dr. Joseph Siebert for teaching me the importance of good medical photography.

\section{REFERENCES}

1. Chan A, Robertson EF, Haan EA, Keane RJ, Ranieri E, Carney A. Prevalence of neural tube defects in South Australia, 1966-91: effectiveness and impact of prenatal diagnosis. $\mathrm{Br}$ Med J 1993;307:703-6.

2. Alembik Y, Dott B, Roth MP, Stoll C. Prevalence of neural tube defects in northeastern France, 1979-94: impact of prenatal diagnosis. Ann Genet 1997;40:69-71.

3. Velie EM, Shaw GM. Impact of prenatal diagnosis and elective termination on prevalence and risk estimates of neural tube defects in California, 1989-91. Am J Epidemiol 1996; 144:473-9.

4. Valdes-Dapena M, Kalousek DK, Huff DS. Perinatal, fetal, and embryonic autopsy. In: Gilbert-Barness E, editor. Potter's pathology of the fetus and infant. Vol. 1. St. Louis: Mosby; 1997. p. 483-524.

5. Larsen S, Rygaard K, Asnaes S, Spang-Thomsen M. Northern and Southern blot analysis of human RNA and DNA in autopsy material. APMIS 1992;100:498-502.

6. Sarnat HB. Muscle pathology and histochemistry. Chicago: American Society of Clinical Pathologists Press; 1983.

7. Giampietro PF, Adler-Brecher B, Verlander PC, Pavlakis SG, Davis JG, Auerbach AD. The need for more accurate and timely diagnosis in Fanconi anemia: a report from the International Fanconi Anemia Registry. Pediatrics 1993;91:111620.

8. Glanz A, Fraser FC. Spectrum of anomalies in Fanconi anemia. J Med Genet 1982;19:412-6.

9. Van den Berg DJ, Francke U. Roberts syndrome: a review of 100 cases and a new rating system for severity. Am J Med Genet 1993;47:1104-23.

10. Auerbach $\mathrm{AD}$, Rogatko A, Schroeder-Kurth TM. International Fanconi Anemia Registry: relation of clinical symptoms to diepoxybutane sensitivity. Blood 1989;73:391-6.

11. Van den Berg DJ, Francke U. Sensitivity of Roberts syndrome cells to gamma radiation, mitomycin $\mathrm{C}$, and protein synthesis inhibitors. Somat Cell Mol Genet 1993;19:377-92. 
12. Chamla Y. C-anaphases in lymphocyte cultures versus premature centromere division syndromes. Hum Genet 1988;78:111-4.

13. Garcia-Higuera I, Kuang Y, D'Andrea AD. The molecular and cellular biology of Fanconi anemia. Curr Opin Hematol 1999; 6:83-8.

14. Clarke AA, Marsh JC, Gurdon-Smith EC, Rutherford TR. Molecular genetics and Fanconi anaemia: new insights into old problems. Br J Haematol 1998;103:287-96.

15. Joenje H, Oostra AB, Wijker M, di Summa FM, van Berkel CG, Rooimans MA, et al. Evidence for at least eight Fanconi anemia genes. Am J Hum Genet 1997;61:940-4.

16. Auerbach AD. Fanconi anemia: genetic testing in Ashkenazi Jews. Genet Test 1997;1:27-33.
17. McLean SD, Saal HM, Spinner NB, Emanuel BS, Driscoll DA. Velo-cardio-facial syndrome. Intrafamilial variability of the phenotype. Am J Dis Child 1993;147:1212-6.

18. Goldberg R, Motzkin B, Marion R, Scambler PJ, Shprintzen RJ. Velo-cardio-facial syndrome: a review of 120 patients. Am J Med Genet 1993;45:313-9.

19. Driscoll DA, Emanuel BS, Mitchell LE, Budarf ML. PCR assay for screening patients at risk for $22 \mathrm{q} 11.2$ deletion. Genet Test 1997;1:109-13.

20. Novelli A, Sabani M, Caiola A, Digilio MC, Gianotti A, Mingarelli $\mathrm{R}$, et al. Diagnosis of DiGeorge and Williams syndromes using FISH analysis of peripheral blood smears. Mol Cell Probes 1999;13:303-7.

\section{Book Review}

\section{Solcia E, Klöppel G, Sobin LH: Histological Typ- ing of Endocrine Tumours. Second Edition, World Health Organisation, International Histological Classification of Tumours, 160 pp, Berlin-Heidelberg, Springer Verlag, 2000 (\$64.50).}

This is an updated and thoroughly revised version of the WHO 'blue book' on endocrine tumors, originally published in 1980 . Prepared by a group of world-renowned pathologists (this time only from Europe and North America), it is a consensus document reflecting our current understanding of endocrine tumor pathology. It was conceived to provide guidance to practicing pathologists, and I am sure that it will be used a great deal. It will help in establishing some uniformity in the nomenclature and, thus, will enable better communication among pathologists from different countries. On the other hand, it is far from being a definitive document, and more like a work in progress. Thus, it also could provide a good basis for broader discussions and stimulate those interested in endocrine neoplasms to explore some of the undefined or controversial entities. It also could be the startline for the next group of pathologists who will carry on the work into the 21 st century.

The editors and the contributors to this mongraph deserve to be congratulated on their effort. As a result of their work, there is a solid WHO classification of tumors, which includes also the most important tumor-like conditions. Obviously these conditions need to be considered when dealing with endocrine tumors, which merge imperceptibly with hyperplasias, dysplasias, and even developmental disorders. The exegetical narrative that follows the classification provides useful definitions and commentaries and is supplemented with well-chosen color photographs. The text contains many useful facts and diagnostic pearls-something for novices and something for more experienced pathologists. Personally, I would have appreciated references supporting some of the statements (especially those that I did not agree with!), and I would urge the powers that be in the WHO to allow the use of references in the next edition.

This reasonably priced booklet belongs in the libraries of all diagnostic pathologists, but it should be used by clinical oncologists as well. As intended, it deserves to be read and used worldwide.

\section{Ivan Damjanov} University of Kansas School of Medicine Kansas City, Kansas 